\title{
Modelling Sustainable Supply Chain Process Considering Cost-Sharing and Stock-Dependence Demand Under Uncertain Environment.
}

Sarat Kumar Jena ( $\nabla$ saratkumar.jena@gmail.com )

Xavier Institute of Management https://orcid.org/0000-0002-6033-5959

Chinmaya Behera

Goa Institute of Management

\section{Research Article}

Keywords: Sustainable supply chain, Cost-sharing, Stock-dependence, Pricing, Renewable energy

Posted Date: January 19th, 2022

DOI: https://doi.org/10.21203/rs.3.rs-1244987/v1

License: (c) (1) This work is licensed under a Creative Commons Attribution 4.0 International License.

Read Full License 
Modelling sustainable supply chain process considering cost-sharing and stockdependence demand under uncertain environment.

\begin{abstract}
Greenhouse gas is one of the major concerns for policymakers and academicians in the modern era. Renewable energy helps to reduce emissions if the industry supply chain is used optimally. Further, there is little understanding of how renewable energy implementation cost and stock dependence simultaneously impact supply chain (SC) profit. Thus, we propose a duopoly sustainable supply chain considering renewable implementation and stock-dependence demand under uncertain environments. A mathematical model is developed for a sustainable supply chain under three scenarios: (i) Renewable energy effort by manufacturer and cost-shared by the retailer (Model M) (ii) Renewable energy effort by retailer and cost-shared by the manufacturer (Model $R$ ), and (iii) Renewable energy effort by both retailer and manufacturer and cost-shared by the manufacturer and retailer (Model C). Nash equilibrium was used to find optimal strategies for players under different integrated channels. The result finds that Model $M$ is comparatively better than the other two models as cost-sharing increases. The result additionally establishes that the total profit decreases as the cost of sharing increases in Model $C$ and Model R, whereas it increases in Model M.
\end{abstract}

Keywords: Sustainable supply chain, Cost-sharing, Stock-dependence, Pricing, Renewable energy.

\title{
1. Introduction
}

The industrial sector consumes about $54 \%$ of the delivered energy, which causes $21 \%$ of the world's carbon emissions (Paris agreement, 2015; IEO, 2016; EW, 2018; Ghadge et al., 2020). Furthermore, using non-renewable energy such as crude oil primarily causes higher greenhouse gases. Alternative energy such as electrical energy, solar energy, etc., helps in reducing the emission. For instance, Germany consumes $47 \%$ of its energy from electrical sources. Further, some organizations use renewable energy as a green technology to combat greenhouse gas emissions (Borges et al., 2019; Zhou et al., 2020). For example, Dell, a leading laptop manufacturer, uses $60 \%$ wind energy for its headquarters. As a result, the company saves nearly $\$ 2$ million in operating costs and reduces carbon emissions by about 12,000 tons each year (RP, 2008). However, organizations must require expensive technology like solar panels (Azevedo et al., 2019; De \& Giri, 2020). For instance, manufacturers and retailers need to consider the cost involved in installing solar panels for renewable energy. Both players can work towards 
renewable energy jointly or independently. For example, Apple, a computer manufacturer, uses $100 \%$ renewable energy on behalf of its distributor, mostly from solar farms, to manufacture and process its products. By using renewable energy, nearly 2.1 million metric tons of carbon dioxide are prevented from entering the atmosphere (AN, 2018). Moreover, Walmart, the world's largest retailer, frequently uses renewable energy and saves approximately 60,000 tonnes of carbon dioxide(Project Gigaton, 2017).

However, for one player to invest in renewable energy does not necessitate that this player must bear all the costs. Cost-sharing has often been implemented in the form of a cooperative strategy for reducing overall renewable energy supply chain costs. For instance, Tata power solar, the largest solar energy manufacturer in India, has provision for sharing rising energy costs with the retailer (TATA Power Solar, 2020). Further, Walmart introduced green supply chains in order to jointly minimize carbon emissions with upstream manufacturers. Franchisees are frequently required to share implementing costs with their franchisors. According to Wang et al. (2016), cost-sharing can reduce $35.9 \%$ of the overall cost compared to without a cost-sharing strategy.

In addition, retailers (such as Walmart) improve efficiency by $25 \%$ when they work with manufacturers (Yi \& Li, 2018: Saberi et al., 2018). However, due to uncertain demand and short selling seasons, manufacturers and retailers have faced many challenges in recent months for selling their short-life cycle products. Short life-cycle products such as vegetables, flowers, fashion apparel, electronic goods, personal computers, etc. that are characterized by uncertain demand and short selling seasons have posed many challenges to the supply chain members (Soni et al., 2008; Parthasarathi et al., 2011). For example, Lau and Lau (2003) pointed out that a slight change in the demand pattern may result in a significant difference in the optimal inventory decisions. Further, demand also plays an important role in market expansion since it depends on many factors, including price, quality, guarantee, advertising, a sales promotion campaign, etc. In addition to this, it has also been found that displaying a greater quantity of a product(such as flowers or vegetables) tends to attract more customers (Zhou and Yang 2005; Ghiami et al., 2020). This fact has attracted the attention of many researchers, and they have incorporated stock-dependence criteria into their demand (You and Hsieh 2007; Bardhan et al., 2019; Wen et al., 2019) while designing cost function. However, deterioration and emissions are natural processes that impact the performance of a product. Therefore, investments in high-quality preservation and green technologies (like renewable 
energy) are necessary to reduce inventory decay and environmental emissions (Mishera et al., 2017, 2020).

In the study of sustainable supply chains, renewable energy implementation (Wee, 2012; Awudu, 2012; Saavedra, 2018; Borges, 2019) and stock-dependency demand (Mishra, 2017; Gharaei, 2019; Mishera, 2020) were considered independently. However, to the best of our knowledge, none of the studies have comprehensively examined renewable energy deployment under uncertain environmental conditions, including cost sharing and stock dependence. Thus, this study contributes to the literature considering stock dependence and cost-sharing in a sustainable supply chain (SSC). The purpose of this paper is to bridge the gap in the literature by addressing the following research questions:

- Considering both cost-sharing and stock dependence under uncertain market demand, what is the optimal selling price, wholesale price, and renewable energy effort?

- Does the optimal stock dependence boost the profit of the SSC under different modes of renewable energy expenditure?

- Are the manufacturer and retailer investing in renewable energy independently or jointly under uncertain market conditions and cost-sharing processes?

- How will cost-sharing affect total supply chain profit under different modes of renewable energy expenditure?

We consider a dual SSC structure to find the answer to those questions. It consists of a manufacturer who manufactures the products, and a retailer purchases that product from the manufacturer and selling to customers. The retailer's demand for customers is presumed to be price and stock dependence sensitive, and the use of renewable energy under uncertain market demand considers business and renewable supply chain efficiency. Based on the mathematical model, we consider optimum cost and effective usage of the manufacturer's renewable energy effort, optimum order quantity, and retail price. We compare the derived results for the operational decision, coordination agreement, and renewable energy performance with three frameworks for sustainable supply chain members.

\subsection{Contribution}

The contributions of our study to the existing literature are threefold. First, the supply chain (SC) coordination principle to achieve an SSC has been recognized in the existing literature (Dong et al., 2016; Jena et al., 2018; Hong \& Guo 2019; Yu et al., 2020). For that, most of the current studies also discussed renewable energy implementation in SSC considering 
coordination strategy (Ahi et al., 2016; Chen et al., 2017; Hafezalkotob 2017; Saghaei et al., 2019; Mafakheri et al., 2020). However, the coordination with cost-sharing and renewable energy efforts under uncertain market demand is missing from the existing literature. Moreover, to the best of our knowledge, this study is the first to develop an analytical model considering both cost-sharing and renewable energy effort under uncertain market demand in a sustainable supply chain. Based on the derived results, manufacturers and retailers will find an equilibrium solution for achieving economic and environmental goals.

Second, manufacturers and retailers believe that increasing the display of a product (e.g., flowers or vegetables) will draw more customers (Zang et al., 2015; Fernando et al., 2018). Moreover, in greenhouses, most produce, such as vegetables and flowers, deteriorates over time. (Mishra 2020). Thus, we take a demand function that is price, stock- dependence, and renewable energy sensitive. Further, renewable energy effort and selling price are considered decision variables to find an optimal solution. The results show that SSC profit increases exponentially for all the modes of renewable energy expenditure as stock dependence increases. Furthermore, we found that stock dependence has a positive effect on SSC's profit under the coordination model when the stock-dependence level is above a specific threshold. Thus, the retailer prefers to induce the renewable energy effort level by sharing the effort cost with the manufacturer. The study will help short life cycles manufacturers make the best decisions about renewable energy efforts, selling prices, and stock shortages for day-to-day decisions.

Finally, our study makes practical implications. Through systematic analysis of optimal use of renewable energy under uncertain market demand, this study findings provide different benefits of managerial decision making. For instance, both manufacturer and retailer derive strategic and operational decisions to achieve economic and environmental goals. Moreover, our finding provides better insights for policymakers to prescribe policy for both the manufacturer and retailer in sustainable supply chain management to promote renewable energy. For instance, the government needs to offer different incentive schemes to encourage renewable energy use.

The remaining sections are organized so that the review of literature is presented in Section 2. Section 3 refers to the model description and assumption. Model development is described in Section 4. Next, a comparative analysis is presented in Section 5, whereas the model using a numerical example is illustrated in section 6 . Section 7 and Section 8 , respectively, discuss 
sensitivity analysis and managerial considerations. We present a conclusion and recommendations for future research in Section 8.

\section{Literature review}

The voluminous research literature is available in the SSC. However, limited work is available in the area of the renewable energy supply chain. The relevant literature is reported under two sub-sections, i.e. (1) Renewable energy uses in the supply chain and (2) Sustainable supply chain coordination.

\subsection{Renewable energy uses in supply chain}

It is observed that operational and economic impact of integrating renewable power sources in a large-scale electricity grid (Watson and AG, 1996). Moreover, Wee et al. (2012) identify that location constraints, conversion cost, and complex distribution networks are the major barrier to renewable energy. They suggest that the involvement of different stakeholders such as the government and researchers can help in removing barriers to renewable energy use. We often find uncertainty in the renewable supply chain. Awudu et al. (2012) find methodologies such as analytical and simulation can be used in solving renewable supply chain issues with uncertainties. Further, De Oliveira et al. (2018) propose a framework of a specific action such as replacing non-renewable energy with renewable for sustainability. Borges et al. (2019) opine demand-side management considering renewable energy generation and propose an auction under time-varying generations by wind and solar units. They observe that household energy storage devices allow consumers to better utilize an energy usage plan. Studies suggest that renewable energy such as biodiesel and biomass supply chain management reduces greenhouse gases to a greater extent (Saavedra et al. 2018, Ramos-Hernández et al., 2020; Mafakheri et al., 2020).

\subsection{Sustainable supply chain coordination}

The coordination and competition strategy optimize the supply chain profit even under uncertain market demand (Jena et al., 2016). Further, Chen et al. (2017) examine the two-part tariff contract and power relationship among supply chain members using a game-theoretic approach. They find that the manufacturer may not exploit the retailer but rather treat them as a strategic partner in sustainable supply chain coordination. Further, Bai et al. (2017) argue that coordination among supply chain members leads to larger profit and lower carbon emission. Also, Hong et al. (2019) find that coordinating agreement between manufacturer and 
retailer is valuable in practice as the consumer gives attention to sustainability and environmental protection

Research literature closely related to the existing literature is summarized in Table 1.

Table 1. Features of previous studies in comparison to our study

\begin{tabular}{|c|c|c|c|c|c|c|}
\hline Authors & $\overline{\text { SSC }}$ & Analytical & $\begin{array}{l}\text { Cost } \\
\text { Sharing }\end{array}$ & $\begin{array}{l}\text { Renewable } \\
\text { Energy/Energy }\end{array}$ & $\begin{array}{l}\text { Uncertain } \\
\text { Market } \\
\text { Demand }\end{array}$ & $\begin{array}{l}\text { Stock } \\
\text { Dependence }\end{array}$ \\
\hline Swami \& Shah (2013) & $\sqrt{ }$ & $\sqrt{ }$ & & & & \\
\hline Xie, G. (2015). & $\sqrt{ }$ & $\sqrt{ }$ & & $\sqrt{ }$ & & \\
\hline Chen et al. (2017) & $\sqrt{ }$ & $\sqrt{ }$ & & $\sqrt{ }$ & & \\
\hline Hafezalkotob (2017) & $\sqrt{ }$ & $\sqrt{ }$ & & $\sqrt{ }$ & & \\
\hline Madani et al.,(2017) & $\sqrt{ }$ & $\sqrt{ }$ & & & & \\
\hline Zhu et al., (2017) & $\sqrt{ }$ & $\sqrt{ }$ & & & & \\
\hline Fernado et al., (2018) & $\sqrt{ }$ & & & $\sqrt{ }$ & & \\
\hline Borges et al.,(2019) & & $\sqrt{ }$ & & $\sqrt{ }$ & & \\
\hline Hong et al. (2019) & $\sqrt{ }$ & $\sqrt{ }$ & $\sqrt{ }$ & & & \\
\hline Mishra et al., (2020) & $\sqrt{ }$ & $\sqrt{ }$ & & & $\sqrt{ }$ & $\sqrt{ }$ \\
\hline $\begin{array}{l}\text { Ramos-Hernández et al. } \\
\text { (2020) }\end{array}$ & $\sqrt{ }$ & $\sqrt{ }$ & & $\sqrt{ }$ & & \\
\hline This Study & $\sqrt{ }$ & $\sqrt{ }$ & $\sqrt{ }$ & $\sqrt{ }$ & $\sqrt{ }$ & $\sqrt{ }$ \\
\hline
\end{tabular}

We understand that no previous study has considered sharing and without sharing as elements of renewable energy implementation processes under uncertain market conditions.

\section{Model illustration and assumption}

We take a dual SSC consisting of a manufacturer and a retailer. The retailer purchases shortlife cycle product such as fashion apparel, mobiles, vegetables, and computers from the manufacturer and sell them to the buyer. The demand faced by the retailer is price, stockdependence, and renewable energy effort sensitive, and the decision variables of retailer are selling price and renewable energy effort. The decision variables faced by the manufacturer are wholesale price and renewable energy effort after green technology investment. Throughout this paper, we use the notations obtained in Table 2.

Table 2: Notations

\begin{tabular}{cl}
\hline Symbol & \multicolumn{1}{c}{ Description } \\
\hline$D$ & Market demand of the respective retailer \\
$Q$ & Order quantity by the retailer \\
$\eta_{i}$ & Cost-sharing between manufacturer and retailer, where $i=m, r$ \\
\hline
\end{tabular}




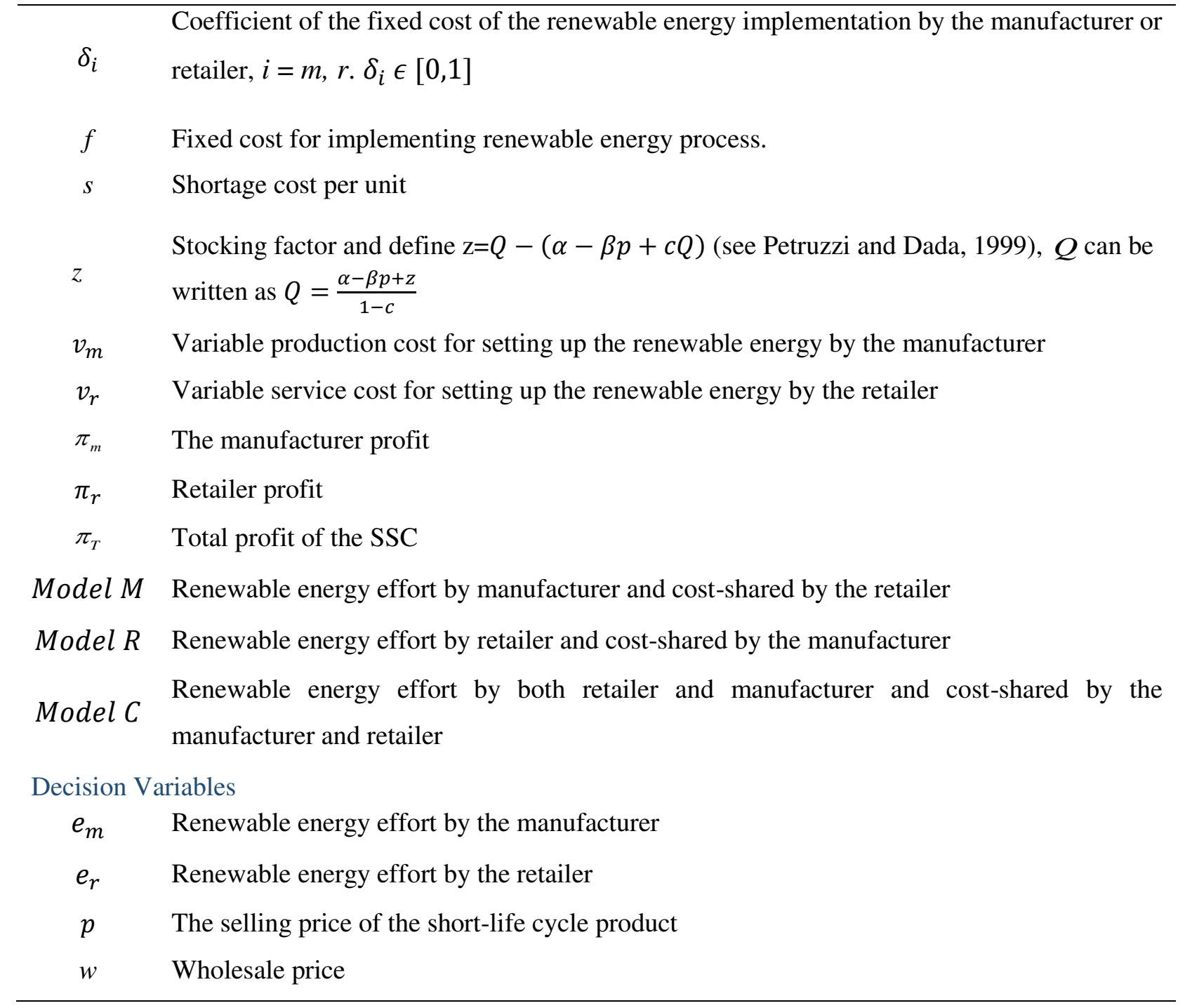

In addition, the following assumptions are considered in this study.

Assumption 1. The duopoly linear market demand is uncertain, price-sensitive, stock dependence, and renewable energy effort sensitive, which captures product differentiation:

$$
D\left(p, e_{m}, e_{r}, \varepsilon\right)=\alpha-\beta p+c Q+I_{m} e_{m}+I_{r} e_{r}+\varepsilon
$$

Here, $\alpha$ is the maximal market demand for the products. $\beta$ measures the consumer's sensitivity to the retailing price of the product, and $c$ is the stock dependence factor. The existing literature uses linear demand extensively relating to pricing and supply chain research as an agreeable estimation of demand (Luo et al., 2016; Jena et al., 2017).

It is presumed that $\alpha>0$ and $\beta>0$, and $\varepsilon$ is random element of the market. In this model, it should be known that there is a probability of positive demand for any period (Petruzzi and Dad, 1999). Therefore, it is known that the random variable $\varepsilon$ has a continuous distribution $F($.$) with a density h($.$) . For the analysis purposes, we assume the random variable is uniformly$ 
allocated in the range $[\mathrm{A}, \mathrm{B}]$ because of the complexity of the model and to know the impact of price and sharing effort on demand. Here, the average market demand of the product represents as $\mu$. Moreover, $I_{m}=1$ or 0 indicates whether the manufacturer performs the renewable energy effort or not. Similarly, $I_{r}=1$ or 0 demonstrates whether the retailer makes renewable energy effort or not respectively. The study limits the focus to the situation in which the SSC contains at least one player performing the renewable energy effort level defined by $I_{m}+I_{r} \geq 1$.

Assumption 2. Both the manufacturer and retailer in the supply chain are risk-neutral.

Early studies of this issue were conducted under the above assumption that the manufacturer and retailer involved in the supply chain were risk-neutral, i.e., they maximize their expected profits (Gan et al., 2005; Wang and Webster, 2005; Jena \& Ghadge, 2020).

Assumption 3. The manufacturer has unlimited potential and is offering its products to its retailer before the beginning of the sales season.

Assumption4: Renewable energy effort cost function is given by $\mathrm{K}\left(e_{r}\right)=\lambda_{r} e_{r}{ }^{2}$ and $\mathrm{K}\left(e_{m}\right)=$ $\lambda_{m} e_{m}{ }^{2}$. Similar to Xie (2015) and Xie et al. (2017), the cost of renewable energy is expressed as:

$$
C_{i}=\left(v_{m}+v_{r}\right) Q+f+\lambda_{i} e_{i}^{2}, \text { when } i=m, r
$$

Where $v_{m} Q$ is the variable production cost, $v_{r} Q$ is the variable service cost, $f$ denotes a fixed cost independent of $e_{i}, e_{m}{ }^{2}$ is the cost of renewable energy effort by the manufacturer and $e_{r}{ }^{2}$ refers cost of renewable energy effort by the retailer. Thus, $C_{i}$ are an increasing and convex function of $e_{i}$. The sustainability initiative is typically modelled as a method of renewable energy expenditure (Smith \&Ball, 2012). More commitment from the retailer and manufacturer to market their product means more spending on sustainability. To allow an average comparison between different SSC systems and for meanness, we assume $\lambda_{m}=\lambda_{r}=1$.

\section{Model development}

This paper develops a mathematical model for an SSC considering the price, stock-dependence, and renewable energy effort sensitivity demand under cost-sharing. Here, the SSC framework divides into three sub scenarios: the renewable effort by the manufacturer, renewable effort by the retailer, and renewable effort by both manufacturer and retailer. In the following subsection, these scenarios of the SSC are discussed in detail. Each sustainable effort scenario is described in three stages. In Stage 1, the potential designed manufacturer commits to renewable 
energy, or not. In Stage 2, the retailer simultaneously sets its product price and levels of renewable energy effort. In Stage 3, a two-echelon SSC is considered under the above models to analyze optimal pricing strategies, amount of renewable energy effort, and selling price.

As noted earlier, here, manufacturers and retailers perform renewable energy investments in the supply chain. Table 3 shows how renewable energy effort is conducted in SSC. Remember that $m$ and $r$ reflect manufacturer and retailer respectively throughout the paper.

Table 3: Parameters specifying how renewable energy effort is made and shared in SSC

\begin{tabular}{ll}
\hline & Cost-sharing \\
\hline Retailer performs renewable energy effort & $I_{r}=1 ; I_{m}=0 ; 0<\eta_{i} \leq 1$ \\
The manufacturer performs renewable energy effort & $I_{r}=0 ; I_{m}=1 ; 0<\eta_{\mathrm{i}} \leq 1$ \\
Both manufacturer and retailer perform renewable energy effort & $I_{r}=1 ; I_{m}=1 ; 0<\eta_{\mathrm{i}} \leq 1$ \\
\hline
\end{tabular}

The supplier here sells the products at a wholesale price and does not require the retailer to make any returns. The leftover items are salvaged without any interest at the close of the sales season. As mentioned earlier, the demand at the retailer is believed to be affected not only by the price and the initial stock level of the item but also by the player's renewable energy effort. Here, it should be noted that the retailer will have to determine both prices, sharing cost, and order quantity simultaneously to maximize their expected profit as the demand is pricesensitive (Liu et al., 2014; Roy et al., 2018). Here, to determine that the cost-sharing effectiveness comes from the framework of renewable energy rather than the individual costsharing rates or channel asymmetry, we unify the cost-sharing levels by letting $\eta_{i}=\eta$. In reality, $\eta$ would result endogenously from the balance of power between the manufacturer and the retailer

The expected profit function of the retailer and manufacturer considering price, renewable energy effort level, and stock dependence factors can be written as:

$$
\begin{aligned}
E\left[\pi_{r}\right] & =p E\left(\min \left(Q, D\left(p, e_{m}, e_{r}, \varepsilon\right)\right)\right)-\left(w+v_{r}\right) Q-s E\left(D\left(p, e_{m}, e_{r}, \varepsilon\right)-Q\right)^{+}-\delta_{r} f \\
& -(1-\eta) I_{r} e_{r}^{2}-\eta I_{m} e_{m}^{2} \\
E\left[\pi_{m}\right] & =Q\left(w-v_{m}\right)-\delta_{m} f-(1-\eta) I_{m} e_{m}^{2}-\eta I_{r} e_{r}^{2}
\end{aligned}
$$

Equation 1 illustrates the retailer's profit function; the first term implies a product's sales revenue, the second represents the purchasing cost, the third term refers to shortage cost, the fourth term indicates the fixed cost of the renewable energy implementation by the retailer $\left(\delta_{r}=\right.$ 1 and $\delta_{m}=0$ ) and the fifth term refers to the renewable energy investment by the retailer, and 
the sixth term indicates the renewable energy investment by the manufacturer with costsharing. Similarly, the first terms in the profit function of the manufacturer (in equation 2) represent the sales profit from a product wholesale, and the second term indicates the fixed cost of the renewable energy implementation by the manufacturer $\left(\delta_{r}=0\right.$ and $\left.\delta_{m}=1\right)$, the third and fourth terms reflect the manufacturer's renewable energy effort and the retailer's renewable energy effort, respectively.

\subsection{Sustainable effort with cost-sharing}

Here, the section is split into three sub-sections which belong to both the manufacturer's renewable energy effort and the retailer's renewable energy effort through sustainable technology investment. In this situation, one participant takes renewable energy effort while the other partner only pays some portion of the total cost for implementing renewable energy process. Here, each member of the SSC tries to maximize the total profit co-ordinately regardless of its impact on the decision of the other member (Jena and Sarmah, 2016). In this case, the retailer forecasts the margin price of the product based on the previous history. We find the manufacturer and retailer to be offering products at the destination. Given the reaction function of the retailer, the manufacturer can take advantage of the profit by determining their wholesale price and renewable energy effort level.

\subsubsection{Renewable energy effort by retailer and shared by the manufacturer(Model R)}

In this situation, the retailer takes an effort for renewable energy, while the manufacturer shares some proportion of renewable energy effort with the retailer. Table 3 here demonstrates how this condition associates with parameter settings. Specifically, $I_{r}=1, I_{m}=0, \delta_{r}=1$, and $\delta_{m}=$ 0 and $0<\eta \leq 1$ respectively, in Eqn. (1) and Eqn. (2) when the retailer drives renewable energy effort; otherwise, $I_{r}=0$.

Here demand function is as follows:

$D\left(p, e_{m}, e_{r}, \varepsilon\right)=\alpha-\beta p+c Q+e_{r}+\varepsilon$

Based on the above assumption, the profit of a retailer and manufacturer can be written as

$$
\begin{aligned}
\operatorname{Max} E\left[\pi_{p, z, e_{r}}{ }^{R}\right] & =p E\left(\min \left(Q, D\left(p, e_{m}, e_{r}, \varepsilon\right)\right)\right)-\left(w+v_{r}\right) Q-s E\left(D\left(p, e_{m}, e_{r}, \varepsilon\right)-Q\right)^{+}-f \\
& -(1-\eta) e_{r}^{2} \\
& =\left(\alpha-\beta p+e_{r}\right) p+\left(\frac{\left(\alpha-\beta p+e_{r}+z\right)}{1-c}\right)\left(p c-w-v_{r}\right)-s \mu+(p+s)\left(z-\frac{(z-A)^{2}}{2(B-A)}\right) \\
& -f-(1-\eta) e_{r}{ }^{2}
\end{aligned}
$$


$\operatorname{Max} E\left[\underset{w}{\pi_{m}{ }^{R}}\right]=\left(\frac{\left(\alpha-\beta p+e_{r}+z\right)}{1-c}\right)\left(w-v_{m}\right)-\eta e_{r}^{2}$

From Equation 4 , it is seen that $\pi_{r}\left(p, e_{r}, z, \varepsilon\right)$ is concave in $p$ for a given $z$.

Proposition 1. When the renewable energy effort by the retailer and shared by the manufacturer (Model $\mathrm{R}$ ) is implemented, the equilibrium solutions of the Model $R$ are as follows:

$p^{R}=\frac{A^{2}(-1+c)+(-1+c) z^{2}+2 B(z+\alpha+w \beta)-2 A(c z+\alpha+w \beta)-2(A-B)\left(e_{r}+\beta v_{r}\right)}{4(B-A) \beta}$

$z^{R}=\frac{A(c p-w)+B(-p+(-1+c) s+w)+(-A+B) v_{r}}{(-1+c)(p+s)}$

$e_{r}^{R}=\frac{p-w-v_{r}}{2(-1+c)(-1+\eta)}$

Proof: Appendix A

By replacing the optimal value of Eq. (6). Eq.(7), and Eq.(8) in Eq. (5), the optimal solution of $w$ can be calculated through the first-order condition. We'll get

$$
\begin{aligned}
& (-1+c)^{2}(p+s)(-1+\eta)^{2}\left(\frac{A^{2}}{A-B}-\frac{4 B p}{(-1+c)^{2}(p+s)}+\frac{4 A c p}{(-1+c)^{2}(p+s)}\right. \\
& +\frac{4 B s}{(-1+c)(p+s)}+\frac{2 B z}{(A-B)(-1+c)}+\frac{2 A c z}{A-B-A c+B c}+\frac{z^{2}}{A-B}+\frac{4 \alpha}{-1+c}+\frac{2 B \alpha}{(A-B)(-1+c)} \\
& +\frac{2 A \alpha}{A-B-A c+B c}-\frac{2 p \eta}{(-1+c)^{2}(-1+\eta)^{2}}+\frac{2 e_{r}}{-1+c}+\frac{2(2 A-2 B+(-1+c)(p+s) \beta) v_{m}}{(-1+c)^{2}(p+s)} \\
& w^{R}=\frac{\left.+\frac{2\left(-\frac{2(A-B)}{p+s}+\beta-c \beta+\frac{\eta}{(-1+\eta)^{2}}\right) v_{r}}{(-1+c)^{2}}\right)}{2\left((p+s)\left(2(-1+c) \beta(-1+\eta)^{2}-\eta\right)+4 A(-1+\eta)^{2}-4 B(-1+\eta)^{2}\right)}
\end{aligned}
$$

Again solving Eqs. (6)-(9) simultaneously, one can get the optimal value of $p^{R^{*}}, z^{R^{*}}, w^{R^{*}}$ and $e_{r}^{R^{*}}$.

The total renewable supply chain profit is given by:

$\pi_{T}^{R}=\pi_{r}^{R}+\pi_{m}^{R}$

\subsubsection{Renewable energy effort by manufacturer and shared by the retailer( Model M)}

Here, the manufacturer takes an effort for renewable energy, while the retailer shares some proportion of sustainable effort with the manufacturer. Table 3 here demonstrates how this condition associates with constraint settings. Exactly, $I_{r}=0, I_{m}=1, \delta_{r}=0, \delta_{m}=1$, and $0<\eta \leq 1$ respectively, in Eqn. (1) and Eqn. (2) when the manufacturer drives sustainable effort; otherwise $I_{m}=0$.

Here demand function is as follows:

$$
D\left(p, e_{m}, e_{r}, \varepsilon\right)=\alpha-\beta p+c Q+e_{m}+\varepsilon
$$


Based on the above assumption, the profit function of a retailer and manufacturer can be written as:

$$
\begin{aligned}
\underset{p, z}{\operatorname{Max} E\left[\pi_{r}^{M}\right]=} & p E\left(\min \left(Q, D\left(p, e_{m}, e_{r}, \varepsilon\right)\right)\right)^{+}-\left(w+v_{r}\right) Q-s E\left(D\left(p, e_{m}, e_{r}, \varepsilon\right)-Q\right)^{+}-\eta e_{m}^{2} \\
& =\left(\alpha-\beta p+e_{m}\right) p+\left(\frac{\left(\alpha-\beta p+e_{m}+z\right)}{1-c}\right)\left(p c-w-v_{r}\right)-s \mu+(p+s)\left(z-\frac{(z-A)^{2}}{2(B-A)}\right) \\
& -\eta e_{m}^{2}
\end{aligned}
$$

$\operatorname{Max} E\left[\underset{w, e_{m}}{\pi_{m}^{M}}\right]=\left(\frac{\left(\alpha-\beta p+e_{m}+z\right)}{1-c}\right)\left(w-v_{m}\right)-f-(1-\eta) e_{m}^{2}$

From Eq. (11), it is found that $\pi_{r}(p, z, \varepsilon)$ is concave in $p$ for a given $z$.

Proposition 2. When the renewable energy effort by the manufacturer and shared by the retailer $(\operatorname{Model} M)$ is implemented, the equilibrium solutions of the Model $M$ follow:

$p^{M}=\frac{A^{2}(-1+c)+(-1+c) z^{2}+2 B(z+\alpha+w \beta)-2 A(c z+\alpha+w \beta)-2(A-B)\left(e_{m}+\beta v_{r}\right)}{4(B-A) \beta}$

$Z^{M}=\frac{A(c p-w)+B(-p+(-1+c) s+w)+(-A+B) v_{r}}{(-1+c)(p+s)}$

\section{Proof: Appendix B}

By replacing the optimal value of Eq. (13) and Eq. (14) in Eq. (12), the value of $w$ and $e_{m}$ can be calculated through the first-order condition. We'll get

$w^{M}=\frac{1}{4(A-B)(2 A-2 B+(-1+c)(p+s) \beta)}\left(A^{2}\left((1+c)^{2} p+(-1+c)^{2} s\right)+4 B^{2}(p+s-c s)+(-1+\right.$

$c)^{2}(p+s) z^{2}+2 A(-2 B(p+c p+s-c s)-(-1+c)(p+s)(c z-\alpha))+2 B(-1+c)(p+s)(z-$

$\alpha)+2(A-B)\left((-1+c)(p+s) e_{m}+(2 A-2 B+(-1+c)(p+s) \beta)\left(v_{m}-v_{r}\right)\right)$

$e_{m}{ }^{M}=\frac{w-v_{m}}{4(-1+c)(-1+\eta)}$

Again solving Eqs. (13)-(16) simultaneously, one can obtain the optimal value of $p^{M^{*}}, z^{M^{*}}, w^{M^{*}}$ and $e_{m}^{M^{*}}$.

The total renewable supply chain profit under Model $\mathrm{M}$ is given by:

$\pi_{T}^{M}=\pi_{r}{ }^{M}+\pi_{m}{ }^{M}$

\subsubsection{Sustainable effort and shared by both the retailer and manufacturer (Model C)}

In this scenario, both the retailer and the manufacturer simultaneously put the renewable energy effort to maximize the total supply chain profit. Here, supply chain players share greening costs, as mentioned among others in the case of Walmart, Coca-Cola, Dell, etc. (Ghosh \& Shah, 
2015; Jena \&Sarmah 2016). In this regard, Model $C$ does not have a role to play in the total profit function. Table 3 illustrates how parameter settings are adapted to that situation. In particular, $I_{r}=1 ; I_{m}=1, \delta_{r}=1, \delta_{m}=1$, and $0<\eta \leq 1$ in Eqn. (1) and Eqn. (2) respectively.

Here, the demand function is as follows:

$$
D\left(p, e_{m}, e_{r}, \varepsilon\right)=\alpha-\beta p+c Q+I_{m} e_{m}+I_{r} e_{r}+\varepsilon
$$

A retailer and manufacturer may write their profit function as:

$$
\begin{aligned}
\operatorname{Max} E\left[\underset{p, z, e_{r}}{\left.\pi_{r}{ }^{C}\right]}\right] & =p E\left(\min \left(Q, D\left(p, e_{m}, e_{r}, \varepsilon\right)\right)^{+}-\left(w+v_{r}\right) Q-s E\left(D\left(p, e_{m}, e_{r}, \varepsilon\right)-Q\right)^{+}\right. \\
& -\delta_{r} f-\eta e_{m}^{2}-(1-\eta) e_{r}^{2} \\
& =\left(\alpha-\beta p+e_{r}\right) p+\left(\frac{\left(\alpha-\beta p+e_{r}+z\right)}{1-c}\right)\left(p c-w-v_{r}\right)-s \mu+(p+s)\left(z-\frac{(z-A)^{2}}{2(B-A)}\right)-f \\
& -\eta e_{m}^{2}-(1-\eta) e_{r}^{2} \\
\operatorname{MaxE}\left[{ }_{w, e_{m}}{ }^{C}\right]= & \left(\frac{\left(\alpha-\beta p+e_{r}+z\right)}{1-c}\right)\left(w-v_{m}\right)-f-(1-\eta) e_{m}^{2}-\eta e_{r}^{2}
\end{aligned}
$$

From Eq. (18), we observed that $\pi_{r}\left(p, e_{r}, z, \varepsilon\right)$ is concave in $p$ and $e_{r}$ for a given $z$.

Proposition 3. When the renewable energy effort by the manufacturer and retailer and shared the renewable energy cost by both the players (Model $C$ ) is implemented, the equilibrium solutions of the Model $C$ are as follows:

Proof: Appendix C

$$
\begin{aligned}
& p^{C}=\frac{A^{2}(-1+c)+(-1+c) z^{2}+2 B(z+\alpha+w \beta)-2 A(c z+\alpha+w \beta)-2(A-B)\left(e_{m}+e_{r}+\beta v_{r}\right)}{4(B-A) \beta} \\
& z^{C}=\frac{A(c p-w)+B(-p+(-1+c) s+w)+(-A+B) v_{r}}{(-1+c)(p+s)} \\
& e_{r}^{C}=\frac{p-w-v_{r}}{2(-1+c)(-1+\eta)}
\end{aligned}
$$

Substituting the value of $p^{C}, z^{C}$, and $e_{r}{ }^{C}$ in Eq. (19), one can obtain the optimal value of $w^{C}$ and $e_{m}{ }^{C}$.

$$
\begin{aligned}
& \left(( - 1 + c ) ^ { 2 } ( p + s ) ( - 1 + \eta ) ^ { 2 } \left(\frac{A^{2}}{A-B}+\frac{z^{2}}{A-B}+\frac{4 \alpha}{-1+c}+\frac{4 A(A-B) c p-2 A(-1+c) c(p+s) z-2 A(-1+c)(p+s) \alpha}{(A-B)(-1+c)^{2}(p+s)}\right.\right. \\
& +\frac{2 B\left(-2 p+\frac{(-1+c)(2 A s-2 B s+(p+s)(z+\alpha))}{A-B}\right)}{(-1+c)^{2}(p+s)}-\frac{2 p}{(-1+c)^{2}(-1+\eta)^{2}} \\
& +1 /\left((-1+c)^{2}(p+s)(-1+\eta)^{2}\right) 2\left((-1+c)(p+s)(-1+\eta)^{2} e_{m}-(-1+c)(p+s)(-1+\eta)^{2} e_{r}\right. \\
& +((p+s)(1+(-1+c) \beta(-1+\eta))+2 A(-1+\eta)-2 B(-1+\eta))(-1+\eta) v_{m} \\
& w^{C}=\frac{\left.\left.\left.+\left(-(p+s)\left(-1+(-1+c) \beta(-1+\eta)^{2}\right)-2 A(-1+\eta)^{2}+2 B(-1+\eta)^{2}\right) v_{r}\right)\right)\right)}{\left(2\left(4 A(-1+\eta)^{2}-4 B(-1+\eta)^{2}+(p+s)\left(-2+2(-1+c) \beta(-1+\eta)^{2}+\eta\right)\right)\right)} \\
& e_{m}{ }^{C}=\frac{w-v_{m}}{4(-1+c)(-1+\eta)}
\end{aligned}
$$


Solving Eqs. (20)-(24) simultaneously, the optimal solution $\left(p^{C^{*}}, z^{C *}, e_{m}{ }^{C^{*}}, e_{r}^{C^{*}}\right.$ and $\left.w^{C^{*}}\right)$ can be derived.

$\pi_{T}{ }^{C}=\pi_{r}{ }^{C}+\pi_{m}{ }^{C}$

Observation 1: Here, $p, z, e_{m}$, and $e_{r}$ will be strictly increasing with stock dependence factor with same proportion under all these cost-sharing models.

Proof: See Appendix

The selling price and renewable energy effort increase with stock dependence in all three models. Additionally, the stock dependence factor is influencing decision variables at the same rate across all three models. Hence, stock dependence creates higher green business opportunities for manufacturers and retailers of short-life cycle products, manages uncertain market demands, and generates higher SSC profits even if the selling price increases.

\section{Comparative analysis}

The essential insights can be obtained by comparing the three sustainable effort approach with the cost-sharing models mentioned above.

Observation 2. Follows the standard relationship between the optimum selling price and the renewable energy effort for all three models: $p^{M} \leq p^{R}<p^{C}$, and $e_{m}{ }^{M}<e_{r}{ }^{R} \leq e_{m}{ }^{C}$. Proof: See Appendix

We observe that in the cost-sharing, the retailer sells a short life-cycle product at a lower price under Model $M$ than the other two models due to the lower renewable energy effort. Here, the retailer shares some proportion of effort costs with the manufacturer. Because of these, the manufacturer does not intend to increase its wholesale price. As a result, the retailer sells the product with a lower selling price than the other two models. Whereas, in Model R, the retailer's renewable energy effort is higher than Model M. Because of closeness to the customers and uncertain market demand, the retailer makes awareness about environmentally sustainable processes among the customers. For that, the retailer put more cost into making these processes than the manufacturer. However, some proportion of the cost is being shared by the manufacturer. Due to the higher shared cost, the manufacturer compensates for this cost by increasing their wholesale price (Liu et al., 2014).

Consequently, the retailer also increases its selling price. It is seen that the retail price of the items in Model $M$ and Model $R$ are equal when the market share is being made by the two 
players equally. Moreover, in Model C, the selling price of the product is higher than in the other two models at the expense of the customers. In addition, both the players put the renewable energy effort jointly in Model C compared to Model M and Model $R$ that causing higher selling prices from a sustainable perspective.

The implications of observation 2 from the basis of an interesting finding of the paper, via-a-vis, the closer an agent is to the market, the more efficient are the implementation of renewable energy for all parties involved in the channel. In addition, the centrally coordinated system leads to the highest investments in renewable energy and highest sales of the product because all decisions are fully coordinated.

Observation 3. In the cost-sharing program, the ordinal relationship of the retailer and manufacturer's profit for all the models is as follows: $\pi_{\boldsymbol{r}}{ }^{R}<\boldsymbol{\pi}_{\boldsymbol{r}}{ }^{M}<\boldsymbol{\pi}_{\boldsymbol{r}}{ }^{C}$ and $\boldsymbol{\pi}_{\boldsymbol{m}}{ }^{M}<\boldsymbol{\pi}_{\boldsymbol{m}}{ }^{R}<$ $\boldsymbol{\pi}_{\boldsymbol{m}}{ }^{C}$. Moreover, the total profit of SSC is as follows: $\boldsymbol{\pi}_{\boldsymbol{T}}{ }^{R}<\boldsymbol{\pi}_{\boldsymbol{T}}{ }^{M}<\boldsymbol{\pi}_{\boldsymbol{T}}{ }^{C}$, when $.52>\eta>.3$. Proof: See Appendix

Here in observation 3 , it is observed that the revenue of the manufacturer and retailer considering stock dependence under uncertain market demand is higher in Model C compared to the other two models. It happened because of the higher sustainable effort, no presence of double marginalization, and selling price at the expense of the customer made by the two players in SSC. Accordingly, the total profit in model $M$ is higher than the other two models. As we discussed in observation 3, the product selling price in Model $\mathrm{R}$ is higher than Model $M$. For that, the price sensitivity customer may not be interested in buying a product, and consequently, the market demand drops. As a result, the overall profit for the retailer decreases in Model $R$ relative to the other two models. In comparison, the rate of decrement in renewable energy effort by Model C is comparatively higher than a renewable energy effort by Model $M$ and Model $R$ up to a specific range. It happens because of a higher effort level that causes higher demand.

Here, the results show that when the retailers are responsible for the sustainable effort, the manufacturers see more merit in sharing some of the renewable energy cost to encourage sufficient buying green product. This holds as long as the cost-sharing rate is not too high because the manufacturer can recover their renewable energy subsidy by increasing the wholesale price. Again, these advantages do not persist when the cost-sharing rate is high, as wholesale prices, and in turn, retail prices, then need to be raised to a level so high that SSC 
profit decreases. Moreover, it will assist operations and supply chain managers in deciding cost-sharing strategies.

\section{Numerical experiment}

Here, a numerical experiment is performed to illustrate the working of our models and valuable insights. As discussed above, it is presumed that demand is price, stock dependence, and renewable energy effort-sensitive and can be modelled as follows:

$D\left(p, e_{m}, e_{r}, \varepsilon\right)=\alpha-\beta p+c Q+I_{m} e_{m}+I_{r} e_{r}+\varepsilon$. Where, $\varepsilon$ is uniformly distributed within the range $[0,100]$ and most of the parameters are considered. Here, most of the parameters are initialized based on the existing literature (Xie 2015; Chen et al., 2017; Xie et al., 2017) for validating the models. Because these pieces of literature have considered renewable energy saving levels in their supply chain models, some parameters, such as sensitivity parameters of demands to stock dependence coefficient and cost-share, are generated according to the experts' opinions. At the same time, they are realistic concerning the case under investigation. Similar types of assumptions have been considered in the previous literature for validating their Model (Xie 2015; Luo et al., 2016; Chen et al., 2017; Jena et al., 2017; Xie et al., 2017). The following values are used for other parameters in the numerical study: $\alpha=100, \beta=3, c=.6, \eta=$ $0.4, f=100, v_{r}=2, v_{m}=2$, and $s=20$ (Xie 2015; Chen et al., 2017; Xie et al., 2017).

Table 4: Result of different models

\begin{tabular}{cccccccccc}
\hline Model & $w$ & $p$ & $e_{r}$ & $e_{m}$ & $z$ & $\mathrm{Q}$ & $\pi_{m}$ & $\pi_{r}$ & $\pi_{T}$ \\
\hline Model R & 28.64 & 54.02 & 48.71 & - & 105.97 & 232 & 4988.41 & 853.351 & 5841.76 \\
Model M & 21.37 & 46.47 & - & 19.14 & 116.96 & 242 & 4121.13 & 2228.68 & 6349.81 \\
Model C & 28.86 & 63.04 & 67.05 & 26.93 & 120.97 & 315 & 5801.09 & 2378.98 & 8180.07 \\
\hline
\end{tabular}

\subsection{Results and discussions}

The result presented in Table 4 exhibits that under the renewable energy supply chain, the total profit is higher in Model $C$ than the other two models, because of the higher selling price and higher sustainable effort at the expense of the customer. Due to the lower impact of uncertain market demand and shortages cost, and higher the cost of renewable energy effort in the coordinated channel, the retailer faces higher demand from the market. As a result, the selling price and renewable energy effort level are higher than the other two models, and therefore the net benefit in the coordinated system is highest. This argument is consistent with the findings of (Parthasarathi et al., 2011; Xie et al., 2015; Chen et al., 2017; Jena et al., 2017; Xie et al., 2017; Hernández et al., 2020: Mafakheri et al., 2020). However, their studies did not consider the stock dependence and cost-sharing simultaneously under different supply chain power 
strategies. This indicates the novelty of this study. On the other hand, the total profit and renewable energy effort are higher in the renewable energy effort by the manufacturer as compared to the renewable energy effort by the retailer under a cost-sharing system. This is an exciting finding, contrary to what we know from previous studies (Chen et al., 2017; Jena et al., 2017; Mafakheri et al., 2020). The most significant observation of this study is that the total profit of the manufacturer is lower in Model M than Model R. These happen because of the lower selling price, lower renewable energy effort level, and higher-order quantity. Moreover, the manufacturer's profit is highest for Model C and lowest for Model M because of the lowest sustainable effort by the manufacturer. Furthermore, the retailer profit is lower in Model $R$ compared to Model M because of the higher renewable energy effort, lower stock dependence level, and higher selling price. Nevertheless, the Model $R$ creates a lower market demand than the Model M because of the higher renewable energy effort level and higher selling price. As a result, the total profit becomes less than Model M. Overall, we infer that the Model C system (i.e., a renewable energy effort by the manufacturer and retailer) is the best option for the SSC members, as it generates the highest total profit. Nevertheless, there is a need to apply the coordination model to align all SSC members' interests on choosing the centralized decisions to synchronize their economic and environmental targets. As observed in the combined model, the manufacturer reduces the wholesale price for the Model R, compensating their profit loss in the centralized decision-making and incentivizing them to adopt the benchmark solutions.

\section{Sensitivity analysis}

We have done extensive sensitivity analysis to study the effect of different parameters on the results.
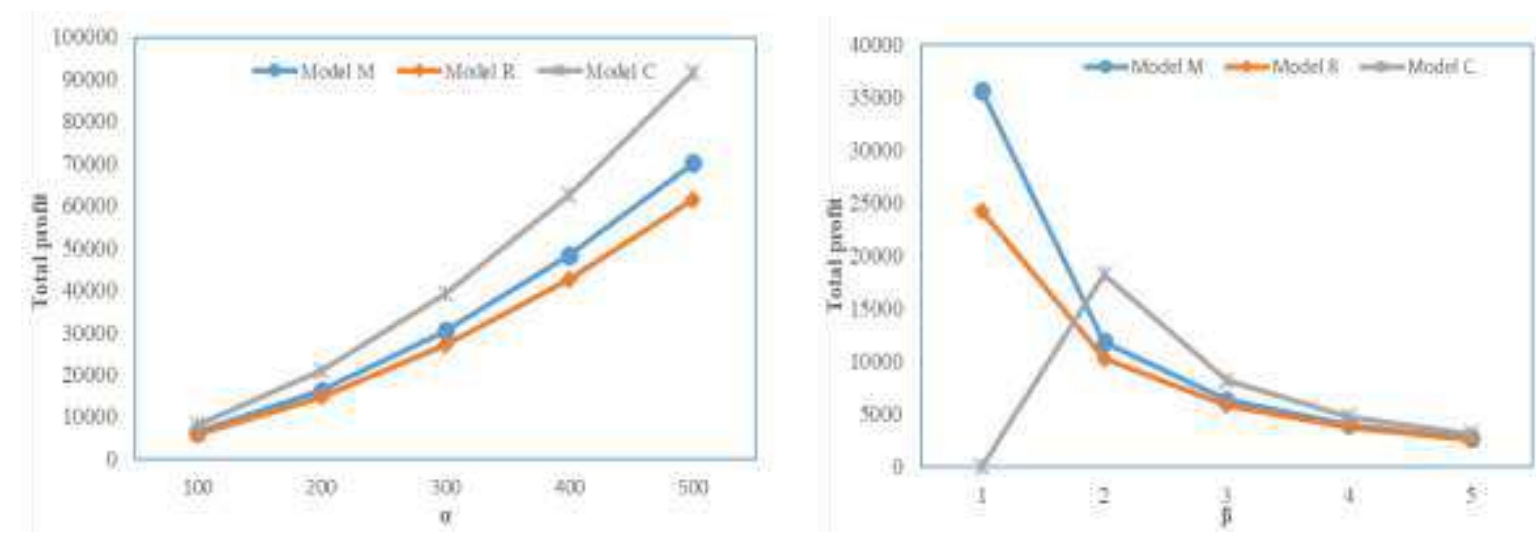

Fig.1: Impact of market size on total profit

Fig.2: Impact of price elasticity on total profit 


\subsection{Effect of market size}

When market size rises, the SSC profit for sharing rises exponentially for all three models (See Fig.1). The study finds that the SSC profit for Model $C$ increases exponentially as the market size, $\alpha$, increases compared with that for the other two models (See Fig 1). It happens because higher sustainable effort causes a higher selling price. The demand for short-life cycle products in Model $M$ rises as the market size increases compared to Model $R$ because of the manufacturer's high renewable energy, generating higher revenue in Model $M$ than that for the Model $R$ system. Again, the manufacturer perceives that the retailer will not be interested in the manufacturer's renewable cost increases. At the same time, in Model R, the retailer thinks to compensate for the extra effort cost by increasing his selling profit. As a result, the gain of the manufacturer increases while the profit of the retailer decreases, tough the total SSC profit is higher in model M compared to Model R. For that, the manufacturer prefers Model $R$ compared to Model M, whereas, retailer prefers Model M compared to Model R as the market size increases. Because of these conflicts' models, both the players conclude to implement Model $C$, compared to other models. Here, both the manufacturer's and retailer's profits increase as market size increases. Thus, the best alternative will be to utilize the Model C framework.
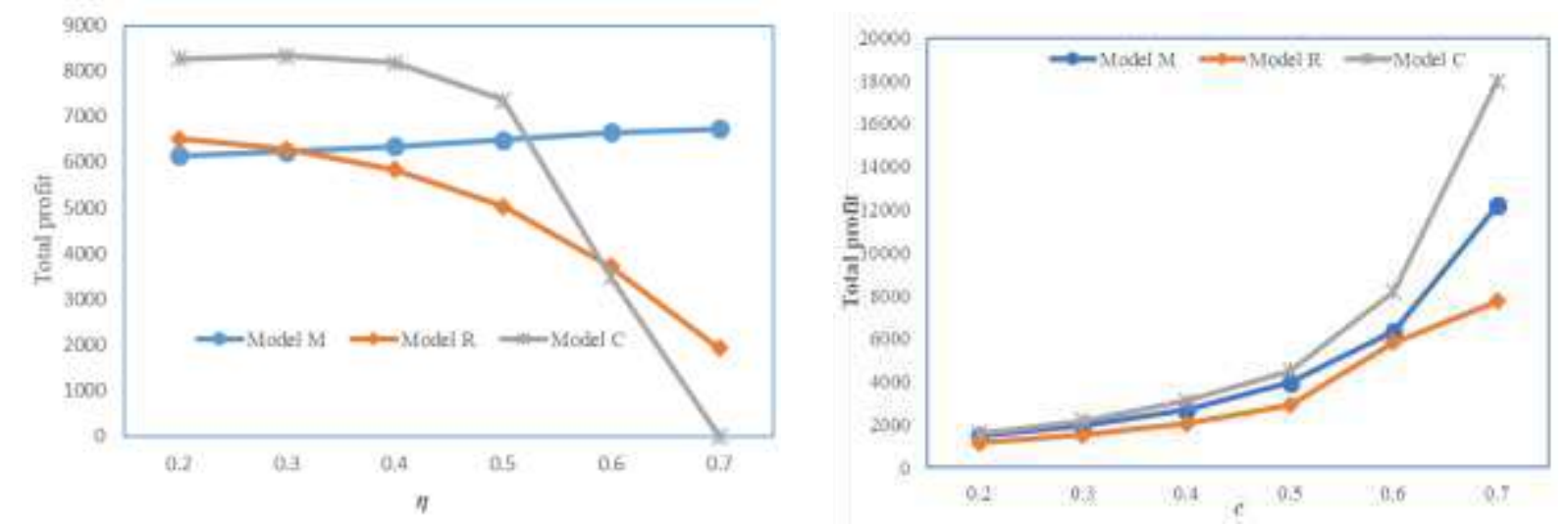

Fig.3: Impact of a cost-sharing factor on total profit. Fig.4: Impact of stock dependence on total profit

\subsection{Effect of the value of price elasticity}

The effect of price elasticity, $\beta$, on the SSC for all frameworks is considered. The outcomes are exhibited in Fig.2; it is seen that the SSC decline exponentially as the price elasticity increases in all the frameworks. When $\beta$ increases, Model $C$ makes more profit than the other two frameworks under cost-sharing because of higher renewable energy effort and higher selling price. Further, it is seen that the total profit under the Model R, Model C, and Model M decreases 
equally as $\beta$ increases after an edge esteem 5. Though it is hardly higher for Model M contrasted and Model $R$ due to higher renewable energy effort. From Fig.2, it is seen that the impact of $\beta$ on Model C is more compared to Model $R$ an edge esteem 1 . Therefore, the best choice will be to utilize Model C after edge esteem 1, and Model M is the best alternative compared with the other two models when $\beta$ increases.

\subsection{Impact of cost-sharing}

We have discussed how various values of sustainable sharing affect SSC profit under different systems. The results are shown in Figure 3. It is found that SSC profit decreases as the estimation of $\eta$ increases in Model $C$ and Model $R$ frameworks. It happens because of a higher proportion of sharing the cost with retailers and without increasing the wholesale price. As a result, the manufacturer's profit and total profit decrease as the value of sharing costs increases. Whereas in Model M, the incremental profit increases as cost-sharing increases.

Moreover, renewable energy effort by the retailer result in higher profit compared to renewable energy effort by the manufacturer as the estimation of $\eta$ increments up to specific edge esteem, 0.3 , and after that renewable energy effort by the manufacturer generates higher profit compared to Model R. It happened because of the lower selling price and higher sustainability effort. However, the rate of decrement in renewable energy effort by the Model $C$ is comparatively higher than a renewable energy effort by Model $R$ up to specific edge esteem, 0.6. Consequently, among these three frameworks, the best alternative will be the renewable energy effort by the manufacturer as the estimation of $\eta$ increases above 0.52 .

\subsection{Impact of stock dependence}

When stock dependence rises, the SSC profit for sharing rises exponentially for all three models (See Fig.4). It is seen that the total profit is highest in Model C and lowest in Model R. As the stock dependence is increased, the coordination benefit is increased. From Figure 4, it is also clear that the rate of improvement of Model C is more at a higher level of stock dependence. It implies that maintaining a higher stock level at the retailer's end has a significant impact on the Model $C$ benefit. Again, the result is valid for all three ranges of demand variability. Though, the total profit in Model $M$ and Model C merge at a threshold point of 0.5. Therefore, the best choice will be to utilize Model $M$ or Model $C$ when the stock dependence reaches a threshold value of 0.5 . In comparison, Model $C$ is the best alternative after edge esteem 0.5 or below 0.5 compared with other frameworks when $c$ increases. This is an exciting finding, contrary to 
what we know from previous studies (Parthasarathi et al., 2011; Chen et al., 2017; Xie et al., 2017; Bardhan et al., 2019 ).

\section{Managerial insights and implication}

Here, we have discussed the implication of this model and the problem of theory and practice.

\subsection{Theoretical implication}

This study has significant theoretical implications in emerging renewable energy implementation and stock-dependence strategy in sustainable supply chain literature. In practice, organizations believe that displaying a greater quantity of products (such as flowers or vegetables) increases market demand (Zhou and Yang 2005; Ghiami et al., 2020). However, it is observed that the high rate of green technology investment is a severe challenge for organizations to reduce $\mathrm{CO}_{2}$ emission, which increases the overall cost significantly. Moreover, many organizations believe that cost-sharing has helped them reduce overall renewable energy implementation costs (Ahi et al., 2016; Chen et al., 2017). Renewable energy implementation has been identified as an essential strategy for reducing the environmental pollution. Thus, today, many organizations invest heavily in renewable energy incorporate social activities to reduce greenhouse gases (Hafezalkotob 2017; Saghaei et al., 2019; Mafakheri et al., 2020).

Further, many organizations that believe in the cost are becoming interested in the bulk amount due to their lower prices and better service than purchasing them separately (Dan et al., 2018). Based on the perspectives of service quality, environmental pollution, and price, this paper extends SSCs research by considering the effects of Model M, Model R, and Model C on supply chain decisions. Furthermore, several studies have indicated the importance of renewable energy implementation (Awudu et al. 2012; Wee et al., 2012; Saavedra et al.,2018; Borges et al., 2019) and stock-dependence demand (Gharaei, 2019; Mishra et al., 2020) on supply chain profit separately. Further, no one has simultaneously considered renewable energy implimentation and stock-dependence in SSC under uncertain environments. In our model, we have considered stock dependence and cost-sharing in SSC. The present study provides a conceptual framework and a mathematical model for optimizing the decision variables by considering all the primary sources of an SSC and the manufacturers', retailers', and integrated frameworks' costs and services. 


\subsection{Managerial implications}

As mentioned in the previous section (see Section 7), the sensitivity analysis may provide some insights into reducing the environmental pollution. The first sensitivity analysis unravels the impact of market size on total SSC profit. With increasing $\alpha$, the value of profit increases, but total SSC cost comes down. So, if an organization only wants to increase total profit through the renewable energy implementation process, it will be good to move for the channel integration process. Moreover, we observed that SSC profit decreases as cost sharing increases in the corrdinated framework, whereas, as the stock-dependence increases, the coordination benefit is increased. Therefore, when a company only wants to increase profits through stockdependence process and not concern itself with the implementation of renewable costs, it will allocate more resources to the Model $C$ system. Moreover, if any manufacturer wants to maximize their profits, it would be better to adopt the Model R model regardless of the service and implementation costs.

Furthermore, with increasing $\eta$ the value of total cost increases, but total supply chain profit under all models comes down. It is observed that after a threshold level, $\eta$ becomes more significant. Then entire supply chain under Model $R$ is lower compared to Model M. So, if organizations only want to increase SC profit with sustainable cost and do not bother about inventory or order quantity, it will be good to adopt Model $M$ after a certain threshold value 3 . Otherwise, the organization can assume Model $R$ with renewable implementation cost irrespective of the service effort. The results indicate that the operations and logistics manager will likely refuse to take on Models $R$ and $C$. It is found that Model $C$ is the best alternative after edge esteem 0.5 or below 0.5 as compared with other frameworks when $c$ increases. Therefore, the retailer manager should disagree with the manufacturer for not sharing renewable energy costs among itself if the sharing cost and stock tendency business model is not profitable.

The SSC needs to develop an environmental policy that reduces greenhouse gases regarding the specific channel structure. Organizations who hesitate to invest in renewable energy or sustainable effort can take advantage of SSC provided in this regard. Some previous studies have investigated this function of displaying products (Mishra et al., 2017; Gharaei, 2019; Mishra et al., 2020). Manufacturers following SSC strategies can collaborate with the retailer to access their cores, especially in industries where providing such a service is inevitable.

\section{Conclusion and future study}


Increasing concerns about the conflicting objectives between manufacturer and retailer make the renewable energy supply chain a complex task. In our study, we examine who will take the responsibility between manufacturer and retailer for renewable energy effort considering stock dependence under the cost-sharing mechanism. In the investigation of SSC, there are three kinds of renewable energy effort strategies (i.e., renewable energy effort by the manufacturer, renewable energy effort by the retailer, and renewable energy effort by both manufacturer and retailer) applied to sell the short term life-cycle product under the cost-sharing system. The retailer can encourage customers to shift from non-sustainability to sustainability by making renewable energy efforts.

Therefore, this study has led to the following significant addition to SSC literature: First, an examination of the framework of the renewable supply chain under various sustainable effort sharing, and find out the optimal solution for each model. Second, mathematical models have been developed to investigate renewable energy effort levels in the presence of price, stock dependence, and renewable energy effort. Finally, a comparison has been made among the three SSC frameworks considering selling price, cost-sharing, and stock dependence level. The main finding of the study that can be used for the practical implications are as follows:

- The total supply chain profit, manufacturer's profit, and retailer's profit are affected by renewable energy effort, stock dependence, and product price. Recognizing these, the manufacturer and retailer can orchestrate the SSC to meet the sustainable supply chain objectives.

- The SSC profit increases exponentially for all three models as stock dependence increases. This reports research question two. It is found that the total profit is highest in Model C and lowest in Model M. As the stock dependence is increased, the coordination benefit is increased. The total profit of SSC under Model C is highly affected by the stock dependence when the stock dependence level is on a specific value of 0.5 . Thus, the retailer prefers to induce the renewable energy effort level by sharing the effort cost with the manufacturer. Because of the presence of stock dependence, the manager of the manufacturing firm and retailer should focus on sharing RE for minimizing the negative impact of the environment and pay attention to the perception of consumers towards sustainable products.

- Among the three frameworks of the SSCs, the Model $R$ scenario has the lowest performance, and Model $C$ has the highest performance in all of the three models. Therefore, it is better for both the manufacturer and retailer to perform renewable 
energy investment jointly under uncertain market demand and cost-sharing processes. This addresses research question three.

- We find that total SSC profit is higher compared to the other two frameworks as market size increases.

- It is observed that Model $M$ is comparatively better than the other two models as costsharing, $\eta$, increases after the edge of 0.52 . Because the total profit decreases as the value of $\eta$ increases in both Model $C$ and Model R, while, in Model M, the total profit increases as cost-sharing increases. This addresses research question four.

Based on the results, the operations and logistics manager will likely refuse to take on the models $\mathrm{R}$ and $\mathrm{C}$. Therefore, the manager of the retailer should disagree with the manufacturer for not sharing RE costs among itself if the sharing cost and stock tendency business model is not profitable.

There are several possible developments for future research. First, the duopoly of the SSC can be extended considering several retailers and manufacturers in SSC with different products in an industry. Second, these models can be developed considering price and renewable energy effort level competition. Third, it is interesting to understand the importance of bargaining power on the renewable energy effort level. Thus, these models can be extended considering the power balance between manufacturer and retailer under game theory. Here, the sustainable effort is considered without seeing product collection and reverse logistics. The manufacturer is responsible differently in the reverse logistics process than the retailer (Jena Sarmah 2016; Saavedra et al., 2018). Thus, it is crucial to analyze stock dependence and effort sharing under uncertain market demand when considering reverse logistics processes. Finally, government subsidies and tax under uncertain market demand would be an interesting future direction.

\section{Appendix}

\section{Proposition 1}

$\boldsymbol{H}\left(\boldsymbol{p}, e_{r}, \mathbf{z}\right)=\left(\begin{array}{lll}\frac{\partial^{2} \pi_{r}{ }^{R}}{\partial p^{2}} & \frac{\partial^{2} \pi_{r}{ }^{R}}{\partial p \partial e_{r}} & \frac{\partial^{2} \pi_{r}{ }^{R}}{\partial p \partial z} \\ \frac{\partial^{2} \pi_{r}{ }^{R}}{\partial e_{r} \partial p} & \frac{\partial^{2} \pi_{r}{ }^{R}}{\partial e_{r}{ }^{2}} & \frac{\partial^{2} \pi_{r}{ }^{R}}{\partial e_{r} \partial z} \\ \frac{\partial^{2} \pi_{r}{ }^{R}}{\partial z \partial p} & \frac{\partial^{2} \pi_{r}{ }^{R}}{\partial z \partial e_{r}} & \frac{\partial^{2} \pi_{r}{ }^{R}}{\partial z^{2}}\end{array}\right)=\left(\begin{array}{ccc}-2 \beta-\frac{2 c \beta}{1-c} & \frac{1}{2 \beta} & -\frac{B-A c-z+c z}{2 A \beta-2 B \beta} \\ 1+\frac{c}{1-c} & -2(1-\eta) & \mathbf{0} \\ 1+\frac{c}{1-c}-\frac{-A+z}{-A+B} & \mathbf{0} & -\frac{p+s}{-A+B}\end{array}\right)$

$\frac{\partial^{2} \pi_{r}^{R}}{\partial p^{2}}<0, \frac{\partial^{2} \pi_{r}^{R}}{\partial e_{r}^{2}}=-2\left(1-\eta<0, \operatorname{det}\left(p, e_{r}\right)>0, \frac{\partial^{2} \pi_{r}^{R}}{\partial z^{2}}<0\right.$, and $\operatorname{det}\left(p, e_{r}, z\right)>0$. 
The hessian matrix here is negative definite. Consequently, the profit function of the retailer is strictly concave in $p, e_{r}$ and $\mathrm{z}$.

$\frac{\partial \pi_{r}^{R}}{\partial p}=0$

$p=\frac{A^{2}(-1+c)+(-1+c) z^{2}+2 B(z+\alpha+w \beta)-2 A(c z+\alpha+w \beta)-2(A-B)\left(e_{r}+\beta v_{r}\right)}{4(B-A) \beta}$

$\frac{\partial \pi_{r}^{R}}{\partial z}=0$

$Z=\frac{A(c p-w)+B(-p+(-1+c) s+w)+(-A+B) v_{r}}{(-1+c)(p+s)}$

$\frac{\partial \pi_{r}^{R}}{\partial e_{r}}=0$

$e_{r}=\frac{p-w-v_{r}}{2(-1+c)(-1+\eta)}$

Proposition 2

$\boldsymbol{H}(p, z)=\left(\begin{array}{ll}\frac{\partial^{2} \pi_{r}{ }^{M}}{\partial p^{2}} & \frac{\partial \pi_{r}{ }^{M}}{\partial p \partial z} \\ \frac{\partial \pi_{r}{ }^{M}}{\partial z \partial p} & \frac{\partial^{2} \pi_{r}{ }^{M}}{\partial z^{2}}\end{array}\right)=\left(\begin{array}{cc}-2 \beta-\frac{2 c \beta}{1-c} & 1+\frac{c}{1-c}-\frac{-A+z}{-A+B} \\ 1+\frac{c}{1-c}-\frac{-A+z}{-A+B} & -\frac{p+s}{-A+B}\end{array}\right)$

$\frac{\partial^{2} \pi_{r}^{M}}{\partial p^{2}}=-2 \beta-\frac{2 c \beta}{1-c}<0, \frac{\partial^{2} \pi_{r}}{\partial z^{2}}=-\frac{p+s}{-A+B}$, and

$\operatorname{det}(p, z)=\frac{B^{2}+A^{2} c^{2}+(-1+c)^{2} z^{2}+2 A(-1+c)(c z+(p+s)(c \beta+\beta-c \beta))+2 B(A c-(-1+c)(z+(p+s)(c \beta+\beta-c \beta)))}{(A-B)^{2}(-1+c)^{2}}>0$

Hence hessian matrix here is definite negative. Therefore, the benefit function of the retailer is purely concave in $p$, and $\mathrm{z}$.

$\frac{\partial \pi_{r}{ }^{M}}{\partial p}=0$

$p=\frac{A^{2}(-1+c)+(-1+c) z^{2}+2 B(z+\alpha+w \beta)-2 A(c z+\alpha+w \beta)-2(A-B)\left(e_{m}+\beta v_{r}\right)}{4(B-A) \beta}$

$\frac{\partial \pi_{r}^{M}}{\partial z}=0$

$Z=\frac{A(c p-w)+B(-p+(-1+c) s+w)+(-A+B) v_{r}}{(-1+c)(p+s)}$

Proposition 3

Proposition 3 can be solved like Proposition 1 and Proposition 2

Observation 1

$\frac{\partial p^{M}}{\partial c}=\frac{\partial p^{R}}{\partial c}=\frac{\partial p^{c}}{\partial c}=\frac{(A-z)^{2}}{4(B-A) \beta}>0$, as $B>A$

$\frac{\partial z^{M}}{\partial c}=\frac{\partial z^{R}}{\partial c}=\frac{\partial z^{C}}{\partial c}=\frac{(B-A)\left(p-w-v_{r}\right)}{(-1+c)^{2}(p+s)}$ as $p-w-v_{r}>0$ 
$\frac{\partial e_{m}{ }^{M}}{\partial c}=\frac{\partial e_{r}^{R}}{\partial c}=\frac{\partial e_{m(r)}{ }^{C}}{\partial c}=\frac{w-v_{m}}{4(-1+c)^{2}(1-\eta)}$, as $w-v_{m}>0$

Observation 2

$\boldsymbol{p}^{M}-\boldsymbol{p}^{R}=\frac{e_{m}{ }^{M}-e_{r}{ }^{R}}{2 \beta} \leq 0$ and found that $\boldsymbol{p}^{M}=\boldsymbol{p}^{R}$, when $e_{m}{ }^{M}-e_{r}{ }^{R}=0$

$e_{m}{ }^{M}-e_{r}^{R}=-2 \beta<0$

$\boldsymbol{p}^{C}-\boldsymbol{p}^{R}=\frac{(\alpha-c \beta)}{2 \beta\left(3-20 \beta+32 \beta^{2}\right)}>0$, because of $\beta>1$

$e_{m}{ }^{C}-e_{r}{ }^{R}=\frac{3 v_{m}-2 v_{r}}{4-4 \eta+4 c \eta} \geq 0$ As $v_{m}>v_{r}$, and $0<\eta \leq 1$

\section{Observation 3}

Proposition 6 can be solved like Proposition 5

So $\pi_{\boldsymbol{T}}^{R}<\boldsymbol{\pi}_{\boldsymbol{T}}^{M}<\boldsymbol{\pi}_{\boldsymbol{T}}{ }^{C}$

\section{Reference}

Ahi, P., Searcy, C., \& Jaber, M. Y. (2016). Energy-related performance measures employed in sustainable supply chains: A bibliometric analysis. Sustainable Production and Consumption, 7, 1-15.

AN (2018): https://www.apple.com/in/newsroom/2018/04/apple-now-globally-powered-by-100percent-renewable-energy/

Awudu, I., \& Zhang, J. (2012). Uncertainties and sustainability concepts in biofuel supply chain management: A review. Renewable and Sustainable Energy Reviews, 16(2), 1359-1368.

Bai, Q., Chen, M., \& Xu, L. (2017). Revenue and promotional cost-sharing contract versus two-part tariff contract in coordinating sustainable supply chain systems with deteriorating items. International Journal of Production Economics, 187, 85-101.

Bardhan, S., Pal, H., \& Giri, B. C. (2019). Optimal replenishment policy and preservation technology investment for a non-instantaneous deteriorating item with stock-dependent demand. Operational Research, 19(2), 347-368.

Borges, Y. G., Schouery, R. C., Miyazawa, F. K., Granelli, F., da Fonseca, N. L., \& Melo, L. P. (2020). Smart energy pricing for demand-side management in renewable energy smart grids. International Transactions in Operational Research, 27(6), 2760-2784.

Carter, C. R., \& Rogers, D. S. (2008). A framework of sustainable supply chain management: moving toward new theory. International Journal of Physical Distribution \& Logistics Management.

Chen, X., Wang, X., \& Chan, H. K. (2017). Manufacturer and retailer coordination for environmental and economic competitiveness: A power perspective. Transportation Research Part E: Logistics and Transportation Review, 97, 268-281.

De, M., \& Giri, B. C. (2020). Modelling a closed-loop supply chain with a heterogeneous fleet under carbon emission reduction policy. Transportation Research Part E: Logistics and Transportation Review, 133, 101813.

Dong, C., Shen, B., Chow, P. S., Yang, L., \& Ng, C. T. (2016). Sustainability investment under capand-trade regulation. Annals of Operations Research, 240(2), 509-531.

EIA(2020); https://www.eia.gov/energyexplained/renewable-sources/ 
EW (2018); https://ecowarriorprincess.net/2018/04/carbon-intensive-industries-industry-sectorsemit-the-most-carbon/

Fernando, Y., Bee, P. S., Jabbour, C. J. C., \& Thomé, A. M. T. (2018). Understanding the effects of energy management practices on renewable energy supply chains: Implications for energy policy in emerging economies. Energy Policy, 118, 418-428.

Gan, X., Sethi, S. P., \& Yan, H. (2005). Channel coordination with a risk-neutral supplier and a downside-risk-averse retailer. Production and Operations Management, 14(1), 80-89.

Ghiami, Y., \& Beullens, P. (2020). The continuous resupply policy for deteriorating items with stockdependent observable demand in a two-warehouse and two-echelon supply chain. Applied Mathematical Modelling, 82, 271-292.

Ghadge, A., Wurtmann, H., \& Seuring, S. (2020). Managing climate change risks in global supply chains: a review and research agenda. International Journal of Production Research, 58(1), 4464.

Ghosh, D., \& Shah, J. (2015). Supply chain analysis under green-sensitive consumer demand and cost sharing contract. International Journal of Production Economics, 164, 319-329.

Hafezalkotob, A. (2017). Competition, cooperation, and coopetition of green supply chains under regulations on energy saving levels. Transportation Research Part E: Logistics and Transportation Review, 97, 228-250.

Hocine, A., \& Kouaissah, N. (2020). XOR analytic hierarchy process and its application in the renewable energy sector. Omega, 97, 102082.

Hong, Z., \& Guo, X. (2019). Green product supply chain contracts considering environmental responsibilities. Omega, 83, 155-166.

IEO (2016); https://www.eia.gov/outlooks/ieo/pdf/industrial.pdf

Jena, S. K., Ghadge, A., \& Sarmah, S. P. (2018). Managing channel profit and total surplus in a closed-loop supply chain network. Journal of the Operational Research Society, 69(9), 13451356.

Jena, S. K., \& Sarmah, S. P. (2016). Price and service co-opetiton under uncertain demand and conditionof used items in a remanufacturing system. International Journal of Production Economics, 173, 1-21.

Jena, S. K., Sarmah, S. P., \& Sarin, S. C. (2017). Joint-advertising for collection of returned products in a closed-loop supply chain under uncertain environment. Computers \& Industrial Engineering, 113, 305-322.

Jena, S. K., \& Ghadge, A. (2020). Product bundling and advertising strategy for a duopoly supply chain: a power-balance perspective. Annals of Operations Research, 1-25.

Lau, A. H. L., \& Lau, H. S. (2003). Effects of a demand-curve's shape on the optimal solutions of a multi-echelon inventory/pricing model. European Journal of Operational Research, 147(3), 530-548.

Liu, B., Cai, G., \& Tsay, A. A. (2014). Advertising in asymmetric competing supply chains Production and Operations Management, 23(11), 1845-1858.

Luo, Z., Chen, X., \& Wang, X. (2016). The role of co-opetition in low carbon manufacturing. European Journal of Operational Research, 253(2), 392-403.

Madani, S. R., \& Rasti-Barzoki, M. (2017). Sustainable supply chain management with pricing, greening and governmental tariffs determining strategies: A game-theoretic approach. Computers \& Industrial Engineering, 105, 287-298.

Mafakheri, F., Adebanjo, D., \& Genus, A. (2020). Coordinating biomass supply chains for remote communities: a comparative analysis of non-cooperative and cooperative scenarios. International Journal of Production Research, 1-18.

Mishra, U., Cárdenas-Barrón, L. E., Tiwari, S., Shaikh, A. A., \& Treviño-Garza, G. (2017). An inventory model under price and stock dependent demand for controllable deterioration rate with shortages and preservation technology investment. Annals of operations research, 254(1), 165-190. 
Mishra, U., Wu, J. Z., Tsao, Y. C., \& Tseng, M. L. (2020). Sustainable inventory system with controllable non-instantaneous deterioration and environmental emission rates. Journal of Cleaner Production, 244, 118807.

Paris agreement (2015) unfccc.int/process-and-meetings/the-paris-agreement/what-is-the-parisagreement.

Petruzzi, N. C., \& Dada, M. (1999). Pricing and the newsvendor problem: A review with extensions, Operations research, 47(2), 183-194.

Project Gigaton(2017); https://www.walmartsustainabilityhub.com/

Parthasarathi, G., Sarmah, S. P., \& Jenamani, M. (2011). Supply chain coordination under retail competition using stock dependent price-setting newsvendor framework. Operational Research, 11(3), 259-279.

Ramos-Hernández, R., Sánchez-Ramírez, C., Sandoval-Salas, F., Manotas-Duque, D. F., RiveraCadavid, L., \& Pérez-Rodríguez, S. I. (2020). Systemic Approach for the Design of Renewable Energy Supply Chain Generated from Biomass. In Techniques, Tools and Methodologies Applied to Global Supply Chain Ecosystems (pp. 259-283). Springer, Cham.

Roy, A., Sana, S. S., \& Chaudhuri, K. (2018). Optimal pricing of competing retailers under uncertain demand-a two-layer supply chain model. Annals of Operations Research, 260(1-2), 481-500.

RP (2008): https://www.reliableplant.com/Read/11282/dell-headquarters-switching-to-100-greenpower.

Saberi, S., Cruz, J. M., Sarkis, J., \& Nagurney, A. (2018). A competitive multiperiod supply chain network model with freight carriers and green technology investment option. European Journal of Operational Research, 266(3), 934-949.

Saghaei, M., Ghaderi, H., \& Soleimani, H. (2020). Design and optimization of biomass electricity supply chain with uncertainty in material quality, availability and market demand. Energy, 197, 117165 .

Saavedra M., M.R., Fontes, C.H.D.O., \& Freires, F. G. M. (2018). Sustainable and renewable energy supply chain: A system dynamics overview. Renewable and Sustainable Energy Reviews, 82, 247-259.

Smith, L., \& Ball, P. (2012). Steps towards sustainable manufacturing through modelling material, energy and waste flows. International Journal of Production Economics, 140(1), 227-238.

Swami, S., \& Shah, J. (2013). Channel coordination in green supply chain management. Journal of the Operational Research Society, 64(3), 336-351.

Tata Power Soloar (2020): https://www.tatapowersolar.com/rooftops/commercial-industrial/

Wang, C. X., \& Webster, S. (2007). Channel coordination for a supply chain with a risk-neutral manufacturer and a loss-averse retailer. Decision Sciences, 38(3), 361-389.

Watson, S. J., \& Ter-Gazarian, A. G. (1996). The optimisation of renewable energy sources in an electrical power system by use of simulation and deterministic planning models. International Transactions in Operational Research, 3(3-4), 255-269.

Wee, H. M., Yang, W. H., Chou, C. W., \& Padilan, M. V. (2012). Renewable energy supply chains, performance, application barriers, and strategies for further development. Renewable and Sustainable Energy Reviews, 16(8), 5451-5465.

Wen, F., Yang, X., \& Zhou, W. X. (2019). Tail dependence networks of global stock markets. International Journal of Finance \& Economics, 24(1), 558-567.

Xie, G. (2015). Modeling decision processes of a green supply chain with regulation on energy saving level. Computers \& Operations Research, 54, 266-273.

Xie, G., Yue, W., \& Wang, S. (2017). Energy efficiency decision and selection of main engines in a sustainable shipbuilding supply chain. Transportation Research Part D: Transport and Environment, 53, 290-305.

Yi, Y., \& Li, J. (2018). Cost-sharing contracts for energy saving and emissions reduction of a supply chain under the conditions of government subsidies and a carbon tax. Sustainability, 10(3), 895.

Yu, Y., Zhou, S., \& Shi, Y. (2020). Information sharing or not across the supply chain: The role of 
carbon emission reduction. Transportation Research Part E: Logistics and Transportation Review, 137, 101915.

You, P. S., \& Hsieh, Y. C. (2007). An EOQ model with stock and price sensitive demand. Mathematical and Computer Modelling, 45(7-8), 933-942.

Zhang, L., Wang, J., \& You, J. (2015). Consumer environmental awareness and channel coordination with two substitutable products. European Journal of Operational Research, 241(1), 63-73.

Zhou, Y. W., \& Yang, S. L. (2005). A two-warehouse inventory model for items with stock-leveldependent demand rate. International Journal of Production Economics, 95(2), 215-228.

Zhu, W., \& He, Y. (2017). Green product design in supply chains under competition. European Journal of Operational Research, 258(1), 165-180.

Zhou, X., Wei, X., Lin, J., Tian, X., Lev, B., \& Wang, S. (2020). Supply chain management under carbon taxes: A review and bibliometric analysis. Omega, 102295. 